\title{
Hydroquinone Synthesis of Silver Nanoparticles from Silver Bromide Suspensions
}

\author{
A. Król-Gracz*, P. Nowak, E. Michalak and A. Dyonizy \\ Institute of Physical and Theoretical Chemistry, Wrocław University of Technology \\ Wybrzeże Wyspiańskiego 27, 50-370 Wrocław, Poland
}

\begin{abstract}
The results of research into the preparation of silver nanoparticles using photoreduction in the presence of hydroquinone as the reductant were discussed. Substrates for the synthesis of silver nanoparticles were ultrafine crystalline gelatine-stabilised aqueous suspensions of silver bromide. The influence of the reductant to substrate molar ratio and the medium's $\mathrm{pH}$ to the efficient production of silver nanoparticles were studied. The properties of resultant silver particles were examined using UV-Vis spectroscopy. Transmission electron microscopy was used for the photomicrography of silver nanoparticles suspensions.
\end{abstract}

PACS: 81.07.-Bc, 61.46.Hk

\section{Introduction}

Silver nanoparticles (Ag NPs) have considerable interest among scientists due to their remarkable properties: antibacterial, catalytic and specific physical and optical properties [1-4]. The use of materials that have silver nanoparticles in their structure includes but is not limited to cosmetics, pharmaceuticals, clothes and in designing solar cells [5-7]. In the last years plenty methods of synthesis for the preparation of Ag NPs have been reported [8-12]. Silver nanoparticles are most often synthesised using chemical reduction. It is silver nitrate and silver perchlorate that are generally used as a source of silver ions during this process, whereas silver nanoparticles are synthesised in the form of a colloid, most often in the presence of a polymer stabiliser (e.g. [13]). Another method of obtaining nanostructured silver is a photolysis of silver salts. The colloidal particles can be achieved and the reduction of metal ions can be controlled through the control of the exposure time with the photolysis [14].

The following paper presents a method for obtaining silver nanoparticles by photoreduction of ultrafine crystalline gelatine-stabilised suspensions of silver bromide. Photoreduction is the combined method, which merges the photolysis and the chemical reduction. Silver nanoparticles are obtained with applying actinic radiation and chemical reductant. An advantage of using $\mathrm{AgBr}$ is that you can maintain a fixed yet appropriately low concentration of silver ions in the solution. Such a concentration results from the thermodynamic equilibrium defined by the solubility product of this salt, which lets silver ions be released slowly to the medium, making it quite easy to control the crystallisation of nanostructural silver. Hydroquinone (HQ) was applied as reducing agent. Silver ions are reduced with hydroquinone in a molar ratio of 2:1, with a surplus of silver ions [15].

\footnotetext{
* corresponding author; e-mail: agnieszka.krol@pwr.wroc.pl
}

This study presents the photoreduction of silver bromide with an initiation by electromagnetic radiation which enables to obtain doped centers in the form of silver clusters on the surface of silver bromide crystals. At a later stage of reduction silver clusters are converted into silver nanoparticles in the presence of hydroquinone. It is shown that hydroquinone in the gelatine medium and slightly basic $\mathrm{pH}$ is an effective reducing agent used for the preparation of Ag NPs only when the reduction reaction was initiated with light. The paper discusses the influence of the reductant to substrate molar ratio on the efficient production of silver nanoparticles.

\section{Experiment}

The reactions were staged in a special darkroom with dark red protective lighting. Suspensions of silver bromide crystals (average diameter $60 \mathrm{~nm}$ ) were used as a substrate for the synthesis of nanoparticles silver. Ultrafine silver bromide suspensions were obtained using method which is described by Dyonizy et al. [16]. $1 \mathrm{ml}$ of $0.333 \mathrm{M}$ silver bromide crystal suspension was put into a reaction vessel in the form of a $100 \mathrm{ml}$ large quartz cuvette, which was then diluted with water down to $70 \mathrm{ml}$. Sodium sulphite was added subsequently, in order to prevent the oxidisation of hydroquinone of oxygen and hydroquinone as the reducing agents. The whole was filled up with redistilled water up to $100 \mathrm{ml}$. The total concentration of the $\mathrm{AgBr}$ crystal suspension in the solution was $3.3 \times 10^{-4} \mathrm{M}$, and that of the gelatine $0.5 \mathrm{~g} / \mathrm{dm}^{3}$. The experiments were conducted with a 2 minute exposition using a halogen lamp (1000 W POLAM LH21) of the reaction mixture, which was being stirred vigorously throughout the whole process of synthesis. The distance of the cuvette from the source of electromagnetic radiation was $20 \mathrm{~cm}$. UV-Vis spectra were generated using an Ocean-Optics USB-4000 fibre optic spectrometer. Transmission electron microscopy (TEM) photomicrographies were made using FEI Tecnai G2 20 X-TWIN microscope, 
with an accelerating voltage of $120 \mathrm{kV}$. Microscope specimens were prepared by depositing the carbon-coated copper grids. The study used analytical purity reagents manufactured by POCH S.A. Poland.

\section{Results and discussions}

Photoreduction was conducted in the presence of actinic radiation or absence of light during the reduction of ultrafine silver bromide suspensions. Hydroquinone was used as the reductant. The impact of the reductant to silver bromide molar ratio: $0.32,0.62,1.60$ and 3.10 in the medium of constant $\mathrm{pH}$ of 8.7 was examined. Fig-

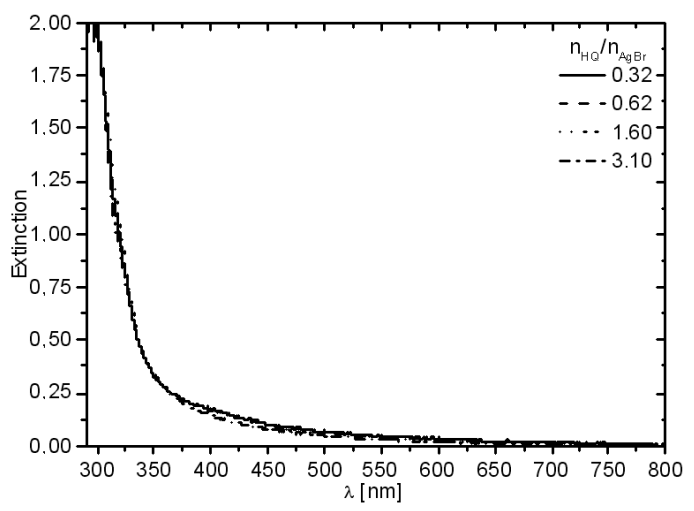

Fig. 1. UV-Vis spectra of silver nanoparticles recorded after $20 \mathrm{~h}$ of the reduction of $\mathrm{AgBr}$ crystals in the presence of hydroquinone and without exposition to light. Molar ratio of $\mathrm{HQ}$ to $\mathrm{AgBr}$ was: $0.32,0.62,1.60$, and 3.10

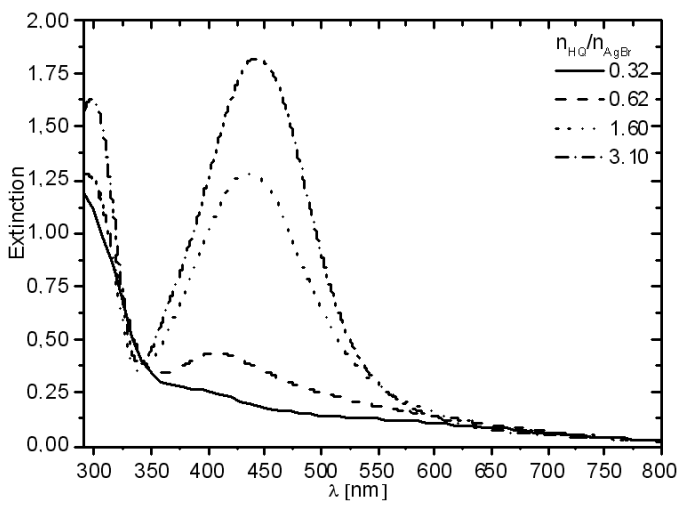

Fig. 2. UV-Vis spectra recorded after $20 \mathrm{~h}$ of the photoreduction of $\mathrm{AgBr}$ crystals in the presence of hydroquinone with 2 min exposition to light. Molar ratio of HQ to $\mathrm{AgBr}$ was $0.32,0.62,1.60$, and 3.10 .

ure 1 presents the UV-Vis spectrum obtained after $20 \mathrm{~h}$ of silver bromide crystals suspensions reduction in the presence of hydroquinone, without exposition to light. It was found that the reduction of ultrafine silver bromide crystals almost do not exist in the studied molar ratios of reactants and $\mathrm{pH} 8.7$ despite the fact the $\mathrm{pH}$

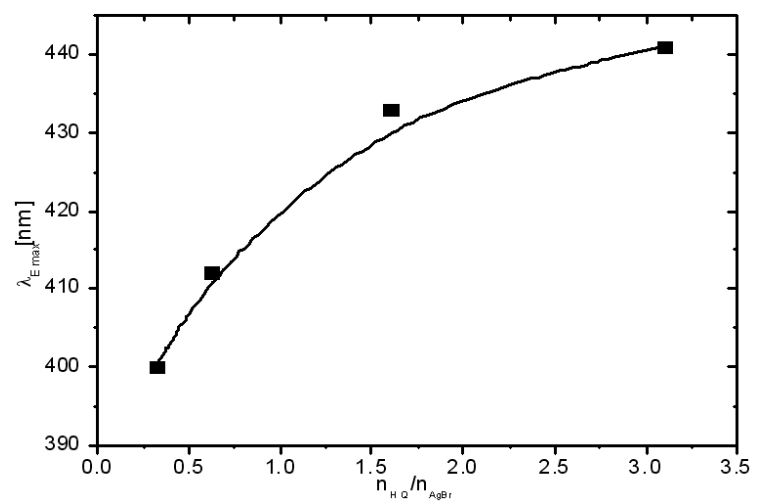

Fig. 3. Position of an extinction band maximum of the $\mathrm{Ag}$ NPs obtained in different molar ratio of $\mathrm{HQ}$ to $\mathrm{AgBr}$ after the photoreduction with exposition to light.

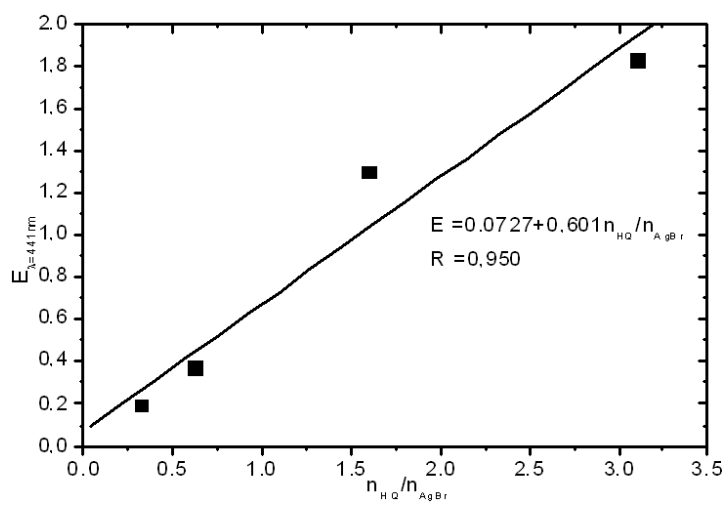

Fig. 4. Maximum extinction of the Ag NPs obtained in different molar ratio of $\mathrm{HQ}$ to $\mathrm{AgBr}$ after the photoreduction with exposition to light.

limit in which the hydroquinone reaches a sufficiently low oxidation-reduction potential to reduce the silver bromide is 7.9 [17]. The probable reason for the lack of reduction reaction in the absence of light, $\mathrm{pH} \mathrm{8.7,} \mathrm{in} \mathrm{the}$ presence of gelatine is too high value of the oxidation-reduction potential barrier at which the hydroquinone does not reduce the crystals of silver bromide to silver. It is necessary to initiate this reaction e.g. by applied actinic radiation allowing the formation of doped centers in the form of clusters of silver on the surface of silver bromide crystals, which are converted into silver nanoparticles in the presence of hydroquinone.

Figure 2 shows the spectral dependence obtained after $20 \mathrm{~h}$ of photoreduction of silver bromide suspensions in different molar ratio of hydroquinone to the substrate and a constant $\mathrm{pH}$ of 8.7 . This process was initiated by 2 min exposure to light of the reaction mixture. Silver nanoparticles obtained at a molar ratio of reductant to AgBr: 0.32, 0.62, 1.60, and 3.10 present the maximum extinction at a wavelength of $398,410,436$, and $440 \mathrm{~nm}$, respectively (Fig. 3). The extinction peaks shifted to longer wavelength and became narrower with the elevated molar 
ratio, possibly due to decreased dispersion of size obtaining silver nanoparticles [18]. The plasmon effect, which is typical of spherically shaped Ag NPs, occurs in range from 390 to $440 \mathrm{~nm}$, relating to size distribution from 4 to $50 \mathrm{~nm}$ [19]. When reductant amount increased in the reaction medium, we observed extinction maximum increase in the range of 0.2 to 3 -fold excess $\mathrm{AgBr}$ relative to HQ and the HQ of 1.8 for the 3 -fold excess of reductant in relation to the substrate (Fig. 4). The results show a good linear correlation with $R=0.950$. Hydroquinone reduction of silver bromide occurs at 2 -fold excess of silver bromide stoichiometrically but reactions carried out in similar conditions $\left(n_{\mathrm{HQ}} / n_{\mathrm{AgBr}}=0.62\right)$ was relatively ineffective. Photoreduction reaction at a $\mathrm{pH}$ of 8.7 was most effective in three excess of hydroquinone (Fig. 2).
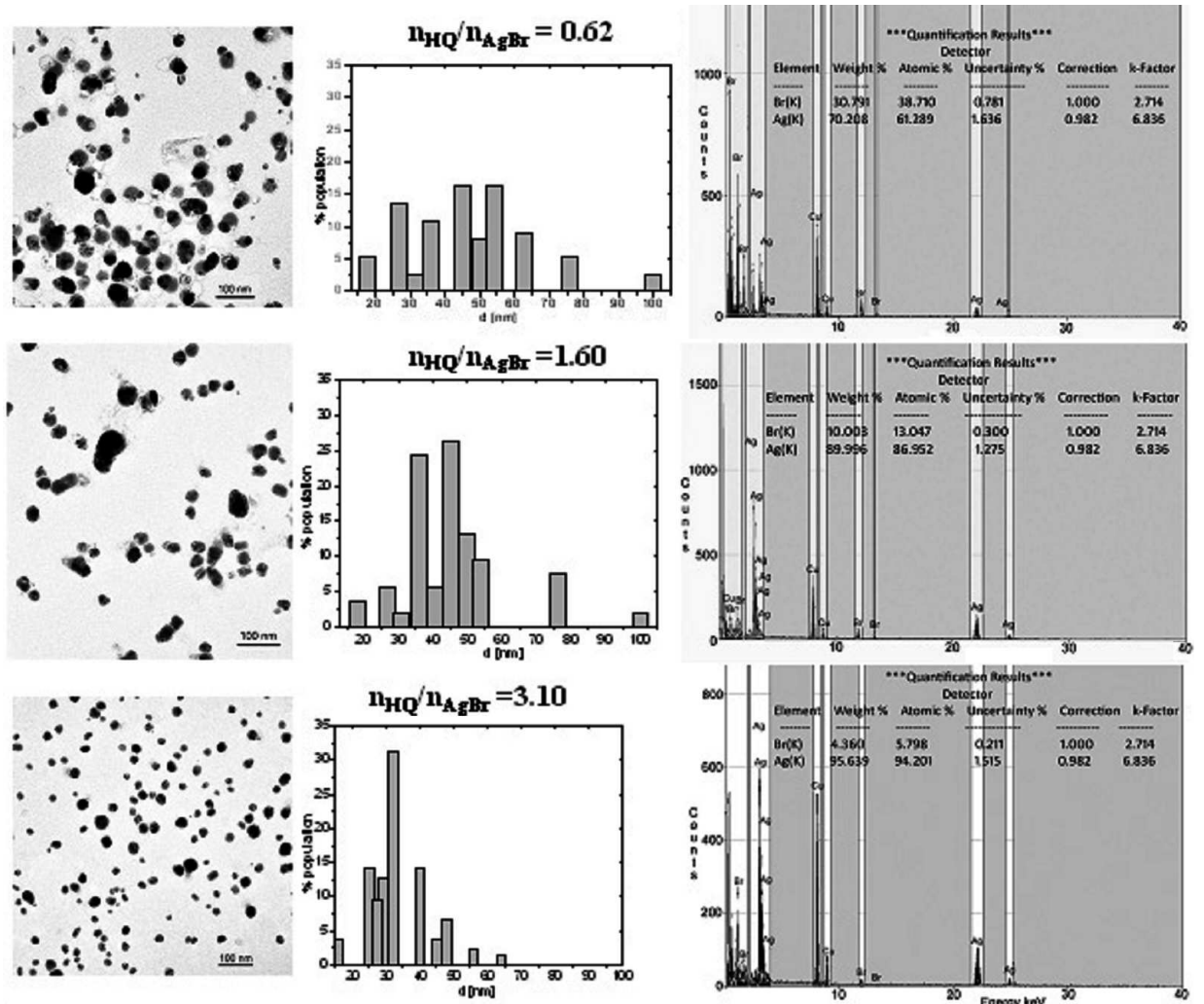

Fig. 5. TEM photomicrographs, size percentage distribution and EDX spectrum of resultant silver nanoparticles obtained using the photoreduction in the presence hydroquinone.

Analysis of the photomicrographs obtained using the TEM method and of chemical composition the energy dispersive X-ray (EDX) of silver nanoparticles (Fig. 5) demonstrated that the growth of molar ratio of hydroquinone to silver bromide causes decrease of average size of silver nanoparticles obtained and decrease the amount of unreacted silver bromide in the range of $30 \%$ for the molar ratio of $\mathrm{HQ}$ to $\mathrm{AgBr} 0.62$ to $4.4 \%$ for the 3 -fold excess of hydroquinone. Population of silver particles obtained in molar ratio reductant to $\mathrm{AgBr}$ of 3.10 has a smaller size and shape dispersion of silver particles than silver obtained in excess of $\mathrm{AgBr}$ as evidenced by the size distribution histograms of silver nanoparticles (Fig. 5). The population of silver nanoparticles obtained at the molar ratio of $\mathrm{AgBr}$ to $\mathrm{HQ} 0.62$ characterized by the dispersion of particle size from $16 \mathrm{~nm}$ to $100 \mathrm{~nm}$ but was dominated by structures with a diameter of $45 \mathrm{~nm}$ and
$54 \mathrm{~nm}$. The resultant population prepared in the 1.6-fold excess of reductant to the substrate was in the size range $18 \mathrm{~nm}$ to $100 \mathrm{~nm}$ but with the dominant population of silver by $35 \mathrm{~nm}$ and $45 \mathrm{~nm}$ in diameter. The most monodisperse of silver nanoparticles was obtained in the population of 3 -fold excess of hydroquinone to $\mathrm{AgBr}$, the average size of silver particles obtained was approximately $30 \mathrm{~nm}$. It can also be concluded from the TEM photomicrographs that the particles obtained are spherically shaped and do not tend to aggregate.

\section{Conclusions}

Described is a method of using the photoreduction, in the presence of hydroquinone as the reductant, of ultrafine crystalline suspensions of silver bromide in a gelatine protection to obtain silver nanoparticles. The paper discusses the influence of the reductant to substrate molar 
ratio on the efficient production of silver nanoparticles. We show that $\mathrm{HQ}$ is unable to reduce isolated silver ions but is able to reduce the same ions when added onto pre-existing silver metallic clusters. In this study we show that UV radiation can be used to initiate the HQ reduction of $\mathrm{AgBr}$ and then the radiation can be removed to allow HQ to finish the Ag NPs growth on its own in dark. TEM analysis confirmed that silver particles formed were shaped almost spherically, with a majority of structures ranging from $15 \mathrm{~nm}$ to $65 \mathrm{~nm}$ in diameter. Tests performed using a spectrometer indicated that it is possible to obtain silver nanoparticles with their maximum extinction rates ranging from 400 to $440 \mathrm{~nm}$. The plasmon effect, which is typical of spherically shaped silver nanoparticles, occurs in this range. The presented method of obtaining nanostructural silver makes it possible to produce silver particles, featuring intense plasmon absorption at a wavelength in the range from $400 \mathrm{~nm}$ to $440 \mathrm{~nm}$, in an easy and efficient way. The resulting colloidal silver has the shape close to spherical and has no tendency to aggregation.

\section{Acknowledgments}

The study conducted under research project N508 488938 is financed from the Ministry of Science and Higher Education for 2010-2011.

\section{References}

[1] K.A. Moores, F. Goettmann, New J. Chem. 30, 1121 (2006).

[2] X. Chen, H.J. Schluesener, Toxicology Lett. 176, 1 (2008).

[3] K. Mallick, W. Witcom, Mater. Chem. Phys. 97, 283 (2006).

[4] S. Wijnhoven, W. Peijnenburg, C. Herberts, W. Hagens, A. Oomen, E. Heugens, B. Roszek, J. Bisschops, I. Gosens, D. van de Meent, S. Dekkers, W. de Jong, M. van Zijverden, A. Sips, R. Geertsma, Nanotoxicology 3, 109 (2009).
[5] P. Gupta, M. Bajpai, S. Bajpai, J. Cotton. Sci. 12, 280 (2008).

[6] E. Vesseur, R. Waele, M. Kuttge, A. Polman, Nano Lett. 7, 2843 (2007).

[7] T. Tolaymat, A. Badawy, A. Genaidy, K. Scheckel, T. Luxton, M. Suidan, Sci. Tot. Environ. 408, 999 (2010).

[8] Y. Qin, X. Ji, J. Jing, H. Liu, H. Wu, W. Yang, Colloids Surf. A 372, 172 (2010).

[9] T. Tsujia, D.H. Thanga, Y. Okazakib, M. Nakanishib, Y. Tsuboic, M. Tsujia, Appl. Surf. Sci. 254, 5224 (2008).

[10] K. Bhainsa, S. D'Souza, Colloids Surf. B 47, 160 (2006).

[11] R. He, X. Qian, J. Yin, Z. Zhu, J. Mater. Chem. 12, $3783(2002)$

[12] J. Talebi, R. Halladj, S. Askari, J. Mater. Sci. 45, 3318 (2010).

[13] J. Widoniak, S. Assmann, G. Maret, Colloids Surf. A 270-271, 340 (2005).

[14] N. Kometani, H. Doi, K. Asami, Y. Yonezawa, Phys. Chem. Chem. Phys. 4, 5142 (2002).

[15] S. Gentry, S. Fredericks, R. Krchnavek, Langmuir 25, 2613 (2009).

[16] A. Dyonizy, P. Nowak, A. Król-Gracz, E. Michalak, Chemik 64, 33 (2010).

[17] T. James, The Theory of the Photographic Process, 4th ed., Macmillan Publishing Co. Inc., New York 1977 , p. 300

[18] M. Cobley, M. Rycenga, F. Zhou, Zhi-Yuan Li, Y. Xia, J. Phys. Chem. C 113, 16975 (2009).

[19] A. Slistan-Grijalva, R. Herrera-Urbina, J. Rivas-Silva, M. Avalos-Borja, F. Castillo-Barraza, A. Posada-Amarillas, Physica E 27, 104 (2005). 